\title{
中国银鱼的多样性及其保护对策
}

\author{
王忠锁 ${ }^{2}$ 傅萃长 ${ }^{2}$ 雷光春 ${ }^{\prime \prime}$ \\ 1 ( 北京大学生命科学学院, 北京 100871) \\ 2 (复旦大学生命科学学院, 上海 200433)
}

摘要: 中国是世界银鱼 (银鱼科 Salangidae 的简称) 的起源地和主要分布区, 在中国东部近海和各大水系的河口共 分布有世界 17 种银鱼中的 15 种, 其中特有种 6 种。银鱼营养价值和经济价值均很高, 是重要的经济鱼类。银鱼生 活周期短、世代离散、生殖力和定居能力强。作为典型的 $r$-对策者, 银鱼对环境变化敏感且反应迅速, 种群消长快, 在漫长的进化过程中形成了其种间食性、生长和繁殖等生物学和生态学特征的丰富的多样性。然而我国的银鱼天 然资源却因围湖造田、过度捕捞、环境污染和生境破碎化等多种因素的影响而持续衰退, 各种银鱼的天然资源都不 同程度地下降, 物种分布范围显著缩小, 个别物种渐危。本文在综述我国银鱼生物学、生态学和生物多样性研究的 基础上, 分析了我国银鱼研究及其物种多样性和种质资源保护工作中所面临的问题; 呼呼审视银鱼移植增殖的生 态效应, 加强银鱼的基本生态学研究和生物多样性保护, 并提出我国银鱼资源保护和可持续利用的对策。

关键词：银鱼,生物学, 种群生态学, 生物多样性, 保护

中图分类号:Q958.1,Q959.4 文献标识码：A 文章编号 : 1005-0094(2002)04-0416-09

\section{Biodiversity of Chinese Icefishes (Salangidae) and their conserving strategies}

WANG Zhong-Suo ${ }^{1}$, FU Cui-Zhang ${ }^{2}$, LEI Guang-Chun ${ }^{1 *}$
1 College of Life Sciences , Peking University , Beijing 100871
2 College of Life Sciences , Fudan University , Shanghai 200433

Abstract : Icefishes ( Salangidae) originated in the Chinese Yellow Sea , and are distributed in eastern Asia. Fifteen out of the 17 global icefish species live in China's coastal area, outflow rivers and estuaries , among which six are endemic to China. The endemic icefishes include Neosalanx oligodontis, $N$. taihuensis , N. pseudotaihuensis , N. tangkahkeii, Hemisalanx brachyrostralis, and Salanx cuvieri. Among all the rivers that flow into the South China Sea, East Sea and Yellow Sea, the Yangtze River has been the most important one for this family, where 10 species live, including five species of freshwater icefishes. Icefishes have been appreciated as a highly nutritious food, and therefore have been a major economic resource in the Yangtze River basin. Icefishes have a wide range of food choices among species, but are very sensitive to their environments ,and they develop quickly, with short life cycles, with discrete generations, high fecundity, and wide population fluctuations, and therefore, they are typical $r$-strategy species. However, due to habitat destruction (wetland reclamation), and fragmentation (dyking), overfishing, and environmental pollution, icefish biodiversity have been declining, and some species have even become vulnerable to extinction. Meanwhile, in the past decade, a few species have been widely introduced into large lakes and reservoirs in China, and have caused problems in the recipient freshwater ecosystem. Based on reviewing the current understanding of their biology, ecology and biodiversity, we present strategies for icefish conservation, and call for an evaluation of the current threats to their biodiversity, as well as of the ecological consequences of icefish introduction, and for strengthening of basic studies on ecology and biodiversity conservation of icefish. 
Key words : icefish , biology, population ecology , biodiversity , conservation

\section{1 引言}

银鱼科 (Salangidae) 鱼类俗称银鱼 (icefish or salangid) ,为一年生小型经济鱼类 (伍献文,1965)。 银鱼为东亚特有类群 (解玉浩, 1997) ,集中分布于 东至 $38^{\circ} 21^{\prime} \mathrm{N}, 141^{\circ} 06^{\prime} \mathrm{E}$;西至 $21^{\circ} 02^{\prime} \mathrm{N}, 105^{\circ} 51^{\prime} \mathrm{E}$; 南 至 $20^{\circ} 01^{\prime} \mathrm{N}, 110^{\circ} 03^{\prime} \mathrm{E} ;$ 北至 $53^{\circ} 08^{\prime} \mathrm{N}, 140^{\circ} 44^{\prime} \mathrm{E}$ 之间 的太平洋西北沿岸亚洲东部的近海、河口及淡水湖 泊中 (张玉玲,1993;刘玉明,2000)。

银鱼研究至今只有 200 多年的历史, 经历了 3 个重要的发展阶段: 1 ) 自 Osbeck (1757) 首次在中 国发现银鱼之后的一百多年时间里, 银鱼研究基本 上是由西方学者进行的分类学和系统学研究 (Regan ,1908 ; Rendahl ,1932;Wakiya Y , 1937)。2) 我国分类学家方秉文对我国银鱼的系统整理和报道 ( Fang,1934a ,b) ,揭开了中国学者研究银鱼的序 幕。银鱼的生物学和生态学的深入研究是这一阶段 的显著特点。20 世纪 80 年代我国学者对几种经济 价值较大的银鱼物种的基本生物学特性作了比较深 入的研究,基本了解了其生活史特征（王文滨， 1980 1982; 张开翔, 1981, 1982, 1984, 1992 ;孙帼英， $1982,1985,1989$; 朱成德，1982，1985; 唐作鹏， 2000 ), 为银鱼的进一步研究奠定了基础。3) 基于 第二阶段的研究成果, 我国银鱼的移植增殖技术研 究和应用研究逐渐发展起来:自 1979 年银鱼首次移 植滇池后, 银鱼的移植和增殖研究工作在我国逐渐 展开，至 20 世纪 90 年代形成高潮 (胡传林,2000)。 而在此阶段中银鱼基本生物学和生态学研究却逐渐 受到冷落。

银鱼营养丰富(蛋白质含量占鲜重的 $12 \%$ $15 \%$ 以上)（熊传喜,1994）, 经济价值较高, 是我国 重要的出口创汇产品,素有 水中的白金”之美誉。 对银鱼经济价值的关注是我国银鱼研究工作的突出 特点, 我国银鱼研究工作始终带有很明显的经济导 向性，与生产实践结合紧密，而缺乏对生态学和保护 生物学的基础研究, 未能系统地把握银鱼资源动态 变化的规律。在银鱼天然资源表现出严重退化的局 面下，很少研究其退化的原因、机制和防止措施，相 反, 却把目光转移到具有短期经济效益的移植养殖 和生产增效上来，忽视了天然银鱼的生物多样性保
护的长期经济效益和生态效益。本文综合近代银鱼 研究的主要成果, 对银鱼分布、生物学和生态学等方 面的特点作全面而简要的综述，同时揭示出我国银 鱼天然资源退化的现状以及研究工作中存在的问 题, 提出银鱼生物多样性保护工作的重要性和紧迫 性, 并提出银鱼生物多样性保护和可持续开发的策 略。

\section{2 银鱼的物种多样性及其空间格局}

银鱼可能起源于第三纪中期的中国北方沿岸 (张玉玲，1993)。地质史上的重大事件，尤其是第 四纪冰期和间冰期气候的交替变化，导致银鱼栖息 地数度隔离和连接, 从而对银鱼的进化分化过程造 成了重大影响。在冰期和间冰期的交替变化过程 中, 银鱼的生境不断地扩展, 生境异质性不断提高, 逐渐分化、进化成现今的银鱼生态格局(张玉玲, 1993 )。

\section{1 物种多样性}

银鱼科属于辐鯺鱼亚纲 (Actinopterygii) ,其科 上和科下分类系统目前均未统一。1990 年以前多 将其列入鲑形目 (Salmoniformes) 的胡瓜鱼亚目 ( Osmeroidei）(成庆泰等，1987），而1990 年以后的欧美 学派的鱼类分类系统则倾向于将银鱼科列于胡瓜鱼 目 (Osmeriformes) 的胡瓜鱼超科 (Osmeroidea) ( Nelson, 1994; 李明德,1998)。本文采用这一较新的分 类系统。同样, 银鱼科的属种分类关系也是众说不 一, 本文参考张玉玲的分类系统将银鱼科分为 2 亚 科 6 属 17 种（张玉玲，1991，1993），包括 8 种淡水 银鱼和 9 种地区特有种 ( 详见表 1 )。

\section{2 空间格局}

银鱼空间分布表现出以中国为中心, 向东、南、 北三方发散并呈递减趋势 (如表 1 所示) :中国分布 有 2 亚科 6 属 15 种 (占 $88.2 \%$ ) ;朝鲜共有 4 属 7 种银鱼 (占 $41.17 \%$ ) ; 目本有 3 属 4 种 (占 $23.53 \%$ ， 含两个特有种); 越南 3 属 3 种 (占 $17.65 \%$ ); 俄罗 斯 2 属 2 种(占 $11.76 \%$ ) (张玉玲, 1991; 1993 ;解玉 浩 ,1997)。

中国是银鱼物种多样性最丰富的国家。首先, 中国拥有全部 6 属银鱼, 且银鱼总物种数、淡水银鱼 物种数 ( 8 种) 和地区特有物种数 (6 种) 均为世界最 
表 1 银鱼的物种多样性及其地理分布

Table 1 The species diversity of icefishes and their geographic distribution

\begin{tabular}{|c|c|c|c|}
\hline $\begin{array}{c}\text { 亚科 } \\
\text { Subfamily }\end{array}$ & $\begin{array}{c}\text { 属 } \\
\text { Genus }\end{array}$ & $\begin{array}{l}\text { 物种 } \\
\text { Species }\end{array}$ & $\begin{array}{l}\text { 主要分布区 } \\
\text { Distributing area }\end{array}$ \\
\hline \multirow[t]{12}{*}{$\begin{array}{l}\text { 新银鱼亚科 } \\
\text { Neosalanginae }\end{array}$} & $\begin{array}{l}\text { 大银鱼属 } \\
\text { Protosalanx }\end{array}$ & $\begin{array}{l}\text { 大银鱼 } \\
P . \text { hyalocranius }\end{array}$ & $\begin{array}{l}\text { 朝鲜半岛西岸，瓯江以北各水系及近岸 } \\
\text { Western coast of Korean Peninsula, coastline and estuaries of Oujiang River and its north- } \\
\text { ern Rivers }\end{array}$ \\
\hline & $\begin{array}{l}\text { 新银鱼属 } \\
\text { Neosalanx }\end{array}$ & $\begin{array}{l}\text { 安氏新银鱼 } \\
N . \text { anderssoni }\end{array}$ & $\begin{array}{l}\text { 朝鲜半岛南、西岸,长江以北水系及近岸 } \\
\text { Western and southern coast of Korean Peninsula ; Yangtze River and other rivers in northern } \\
\text { China }\end{array}$ \\
\hline & & $\begin{array}{l}\text { 短吻新银鱼 } \\
N . \text { brevirostris }\end{array}$ & $\begin{array}{l}\text { 南流江以南水系及沿岸, 红河 } \\
\text { Honghe River , Nanliu River and its southern river basins of China }\end{array}$ \\
\hline & & $\begin{array}{l}\text { 寡齿新银鱼 } \\
N . \text { oligodontis }\end{array}$ & $\begin{array}{l}\text { 海河、淮河、长江水系及沿岸, 中国特有种 } \\
\text { Estuaries of Haihe, Huaihe, and Yangtze River ; Endemic to China }\end{array}$ \\
\hline & & $\begin{array}{l}\text { 太湖新银鱼 } \\
\text { N. taihuensis }\end{array}$ & $\begin{array}{l}\text { 黄河至瓯江水系及沿岸, 中国特有种 } \\
\text { Area between Yellow River and Oujiang River ; Endemic to China }\end{array}$ \\
\hline & & $\begin{array}{l}\text { 近太湖新银鱼 } \\
\text { N. pseudotaihuensis }\end{array}$ & $\begin{array}{l}\text { 黄河至瓯江水系及沿岸, 中国特有种 } \\
\text { Area between Yellow River and Oujiang River ; Endemic to China }\end{array}$ \\
\hline & & $\begin{array}{l}\text { 陈氏新银鱼 } \\
N . \text { tangkahkeii }\end{array}$ & $\begin{array}{l}\text { 长江、闽江、韩江水系及沿岸,中国特有种 } \\
\text { Estuaries of Yangtze River, Minjiang and Hanjiang River ; Endemic to China }\end{array}$ \\
\hline & & $\begin{array}{l}\text { 银色新银鱼 } \\
N . \text { argentea }\end{array}$ & $\begin{array}{l}\text { 朝鲜半岛西岸,海河、韩江、南流江 } \\
\text { Western coast of Korean Peninsula ; Estuaries of Haihe River, Hanjiang River and Nanliu } \\
\text { River }\end{array}$ \\
\hline & & $\begin{array}{l}\text { 乔氏新银鱼 } \\
N . \text { jordani }\end{array}$ & $\begin{array}{l}\text { 朝鲜半岛西岸一鸭绿江 } \\
\text { Western coast of Korean Peninsula ; Estuary of Yalu River }\end{array}$ \\
\hline & & $\begin{array}{l}\text { 雷氏 新银鱼 } \\
\text { N. reganius }\end{array}$ & $\begin{array}{l}\text { 日本九州西岸 ,日本特有种 } \\
\text { Western coast of Kyushu; Endemic to Japan }\end{array}$ \\
\hline & $\begin{array}{l}\text { 日本银鱼属 } \\
\text { Solangichthys }\end{array}$ & $\begin{array}{l}\text { 小齿日本银鱼 } \\
\text { S. microdon }\end{array}$ & $\begin{array}{l}\text { 俄黑龙江口以南,图门江 朝鲜东岸,日本 } \\
\text { Estuary between Heilong River and Tumen River ; Eastern coast of Korea ; Japan mainly }\end{array}$ \\
\hline & & $\begin{array}{l}\text { 石川日本银鱼 } \\
\text { S. ishikawae }\end{array}$ & $\begin{array}{l}\text { 日本九州西岸、本州东岸，日本特有种 } \\
\text { Western coast of Kyushu ; Tumen River ; Eastern coast of Honshu ; Endemic to Japan }\end{array}$ \\
\hline \multirow[t]{5}{*}{$\begin{array}{l}\text { 银鱼亚科 } \\
\text { Salanginae }\end{array}$} & $\begin{array}{l}\text { 间银鱼属 } \\
\text { Hemisalanx }\end{array}$ & $\begin{array}{l}\text { 前领间银鱼 } \\
\text { H. prognathus }\end{array}$ & $\begin{array}{l}\text { 朝鲜半岛西岸, 海河, 长江至瓯江 } \\
\text { Western coast of Korean Peninsula ; Estuary of Haihe River and Rivers between Yangze and } \\
\text { Huaihe River }\end{array}$ \\
\hline & & $\begin{array}{l}\text { 短吻间银鱼 } \\
\text { H. brachyrostralis }\end{array}$ & $\begin{array}{l}\text { 长江中下游及沿江大中型湖泊, 长江特有种, 易危 } \\
\text { Mid-lower reaches of Yangtze River basin ; Vulnerable ; Endemic to China }\end{array}$ \\
\hline & $\begin{array}{l}\text { 白肌银鱼属 } \\
\text { Leucosoma }\end{array}$ & $\begin{array}{l}\text { 白肌银鱼 } \\
\text { L. chinensis }\end{array}$ & $\begin{array}{l}\text { 灵江一瓯江至越南红河各水系及沿岸 } \\
\text { Estuaries of Lingjiang-Oujiang River to Honghe River }\end{array}$ \\
\hline & $\begin{array}{l}\text { 银鱼属 } \\
\text { Salanx }\end{array}$ & $\begin{array}{l}\text { 有明银鱼 } \\
\text { S. ariakensis }\end{array}$ & $\begin{array}{l}\text { 日本、朝鲜、中国东部水系、越南 } \\
\text { Japan，Korea，Eastern China and Vietnam }\end{array}$ \\
\hline & & $\begin{array}{l}\text { 居氏银鱼 } \\
\text { S. cuvieri }\end{array}$ & $\begin{array}{l}\text { 㴒河以南至钦江各水系及沿岸,中国特有 } \\
\text { Estuaries between Luanhe River and Qinjiang River ; Endemic to China }\end{array}$ \\
\hline
\end{tabular}

注 数据引自张玉玲 (1993) 解玉浩(1997) * 示非中国种

Note : Cited from Zhang (1993), Xie (1997) * Non-Chinese species

多( Fang ,1934a ,b ;张玉玲,1993)。其次，中国银鱼 的天然分布范围非常广泛: 从黄、渤海到北部湾的沿 岸 5 20 km 的近海区以及黑龙江、鸭绿江、辽河、海 河、长江、钱塘江和珠江等东部水系的广大区域均有 分布(见表 1 ) ( 孙帼英 ,1982 ;张玉玲,1993 ; 唐作鹏， 1998 )。可见, 中国是世界银鱼的主要分布区, 其银 鱼多样性资源及其保护状况对世界银鱼的续存和发 展具有举足轻重的作用。长江流域是世界银鱼保护 的关键性区域。比较中国东部沿海的 15 个入海水
系 (包括入海口以及近岸带海域) 的银鱼物种多度 (species abundance) (见图 1) 可以发现:中国银鱼物 种多度的空间差异明显, 长江流域的银鱼物种数和 淡水银鱼物种数居各流域之首, 且以长江为中心, 银 鱼物种多样性向南、北方向呈现出非常明显的渐减 趋势。因此, 长江流域为当今世界银鱼分布格局的 核心, 在银鱼的生物多样性保护中的地位是极其重 要的。 


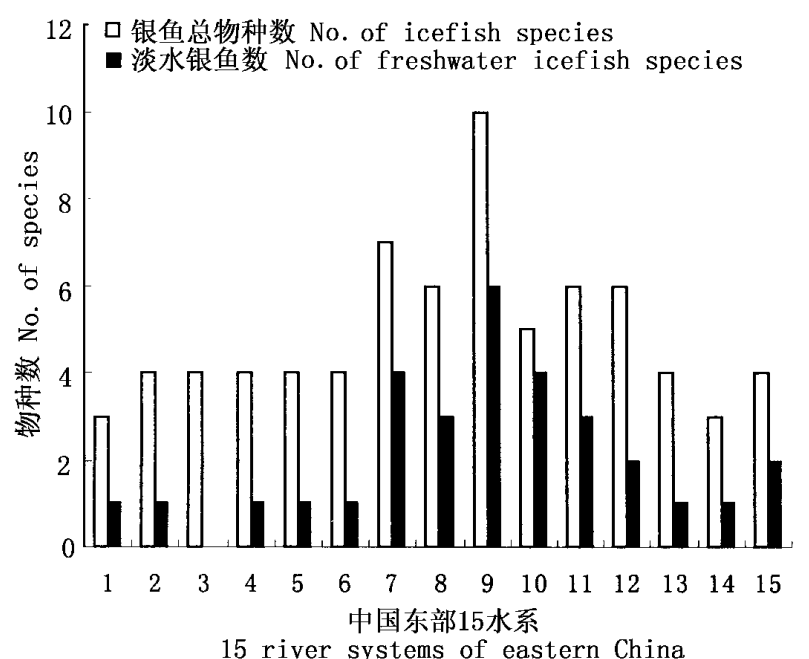

图 1 中国自南向北主要入海水系及河口/近海银鱼多样性

Fig. 1 The species diversity of icefishes in the 15 main rivers and their estuaries along Chinese eastern coastline

图中横坐标自左向右为: 1 北伦河 2 钦江 ; 3 南流江 ; 4 珠江 ;5 韩江 ; 6 闽江一九龙江 ; 灵江一鸥江;8 钱塘江 ; 9 长江; 10 淮河; 11 黄河; 12 海河; 13 㴒河; 14 辽河; 15 鸭绿江的河口与近海。数据参考孙帼 英 (1982) 张玉玲 (1993) ,唐作鹏 (1998)

1 :Beilun River, 2 :Qinjiang River, 3 :Nanliu River , 4 :Zhujiang River, 5 :Hanjiang River , 6 :Minjiang River-Jiulong River , 7 :Lingjiang RiverOujiang River , 8 :Qiantang River , 9 :Yangtze river, 10 :Huaihe River , 11 :Yellow River , 12 : Haihe River , 13 :Luanhe River , 14 :Liaohe River , 15 :Yalu River. Data referring to Sun ( 1982 ) ,Zhang (1993) and Tang ( 1998 )

\section{3 银鱼基本生物学特征的多样性}

银鱼为一年生鱼类,生命周期短,生活史简单; 生长速度快, 世代离散, 繁殖群体 $100 \%$ 为补充群 体, 银鱼生殖力强, 缺乏亲代抚育行为, 幼仔鱼成活 率低(施炜纲，1998）;对环境变化敏感且反应迅速， 种群消长频繁且波动幅度大 ( 朱成德, 1982;张世 东,1999)。移植经验也表明银鱼种群恢复能力和 定居能力强 移入新的生态系统后, 会很快形成种群 甚至分化出新的繁殖群体（高礼存，1989）, 并对本 地物种和生态系统产生深远的影响 (Xie ,1999)。因 此银鱼的生活史对策为典型的 $r$-对策者, 长期的适 应进化导致银鱼物种间在食性、生长和繁殖等方面 表现出丰富的多样性特征。

\section{1 食性}

银鱼的食谱较广, 从浮游动物 (以浮游动物为 主, 轮虫和浮游植物少见, 原生动物极少) 到小型鱼 虾(陈宁生, 1956; 朱成德, 1985; 刘正文, 1994; 龚世 园，1999; 何文辉，2000）。且银鱼的食物组成随个体 的发育而有规律地变化: 各种银鱼的开口食物和早
期主要食物成分都是浮游生物, 其后银鱼的饵料生 物表现出明显的大型化趋势（荣长宽，1998），同时 种间食性差异也逐渐表现出来: 寡齿新银鱼、太湖新 银鱼和近太湖新银鱼等终生以浮游生物为食 (刘正 文，1994; 殷国俊，1997），而大银鱼、有明银鱼等则具 有明显的转食行为: 体长 $45 \mathrm{~mm}$ 以上的个体的食谱 中浮游生物的比重逐渐减小, 小型鱼虾逐渐成为其 主要的食物成分 (张开翔, 1981; 荣长宽,1998; 赫广 春 2000)。

银鱼对食物的选择性是其自身摄食器官的结构 (何文辉 2001)、摄食能力 (Pyke,1984) 及饵料生物 的可获得性 (Gumáa ,1978) 等因素间复杂的相互作 用的结果。银鱼总是倾向于选择体积较大的饵料生 物（刘正文，1994），但其自身的鰓耙结构、口裂宽度 等摄食器官结构限制了其对大型饵料生物的有效摄 取（何文辉，2001）,同时环境因素也可以通过影响 饵料生物的相对丰度和可获得性而间接地影响银鱼 的捕食效率和食物选择性, 并可进一步导致其种群 大小的波动 (黄真理 2001)。

\section{2 生长}

银鱼的生命周期短, 生长迅速, 其早期生长主要 表现为体长的快速增加, 而体重生长却明显滞后。5 $\sim 9$ 月龄是银鱼生长最快的季节, 此时正值水温较 高的 6 9 月份，水温适宜，饵料生物丰富，是银鱼生 长的黄金季节。9 月龄以后银鱼体长和体重接近成 体 增长趋缓( 朱成德, 1985; 王玉芬, 1992; 王卫民， 1996 ;陈国华,1991; 高礼存, 1989; 殷国俊 ,1997)。

表 2 对比了 4 种常见银鱼的体重 - 体长生长方 程 $\left(W=a \cdot L^{b}\right)$ 中的重要生长参数 $a 、 b$ 的回归分析 结果 ( $a 、 b$ 为生长特征常量)。结果表明:几种银鱼 的生长参数 $b$ 均接近 3 , 接近理想的等速生长; 而参 数 $a$ 的悬殊则体现了各种银鱼种间体形和肥满度的 多样性特征, 同时也反应了银鱼体重 - 体长生长的 种间差异。

\section{3 繁殖}

银鱼的性腺发育周期为 12 个月, 其左右两个卵 巢不同步发育,多为两次产卵类型, 生殖群体 $100 \%$ 为补充群体 (张开翔,1981; 殷国俊, 1997; 孙帼英, 1985 )。银鱼产沉水性卵, 受精卵沉于水底发育。 其受精卵具卵膜丝，卵吸水后卵膜丝展开，可以减缓 卵下沉的速度, 同时在卵沉到水底后, 卵膜丝可以支 撑受精卵, 使之不陷入湖底淤泥或附于其他物体上 
表 24 种常见淡水银鱼的体重 - 体长生长参数

Table 2 Growth parameters ( weight-length) of four common freshwater icefish species

\begin{tabular}{|c|c|c|c|c|}
\hline \multirow{2}{*}{$\begin{array}{c}\text { 物种 } \\
\text { Species }\end{array}$} & \multirow{2}{*}{$\begin{array}{l}\text { 湖泊 } \\
\text { Lakes }\end{array}$} & \multicolumn{3}{|c|}{ 体重 - 体长关系 $W=a L^{b}$} \\
\hline & & $a\left(\times 10^{-6}\right)$ & $b$ & $r$ \\
\hline 大银鱼 Protosalanx hyalocranius & 太湖 Taihu Lake & 3.981 & 2.936 & 0.999 \\
\hline 太湖新银鱼 Neosalanx taihuensis & 滇池 Dianchi Lake & 2.720 & 3.409 & 0.997 \\
\hline 近太湖新银鱼 N. pseudotaihuensis & 徐家河水库 Xujiahe Reservoir & 2.014 & 3.170 & 0.999 \\
\hline 寡齿新银鱼 $N$. oligodontis & 网湖 Wanghu Lake & 0.545 & 3.537 & 0.991 \\
\hline
\end{tabular}

表中数据引自朱成德 (1985) ,王玉芬,1992 王卫民 (1996) ,陈国华 (1991) ,高礼存 (1989) 和殷国俊 (1997)

Data from Zhu (1985), Wang (1992), Wang (1996), Chen (1991) , Gao (1989) and Yin (1997)

表 34 种常见银鱼的卵巢发育周期表

Table 3 The ovary development cycles of four common icefish species

\begin{tabular}{|c|c|c|c|c|c|c|c|c|c|c|c|c|c|}
\hline \multirow{2}{*}{\multicolumn{2}{|c|}{ 物种 Species }} & \multicolumn{12}{|c|}{ 月份 Month } \\
\hline & & 12 & 1 & 2 & 3 & 4 & 5 & 6 & 7 & 8 & 9 & 10 & 11 \\
\hline \multicolumn{2}{|c|}{$\begin{array}{l}\text { 大银鱼 } \\
\text { Protosalanx hyalocranius }\end{array}$} & IV $-\mathrm{V}$ & IV $-\mathrm{V}$ & $\mathrm{V}-\mathrm{VI}$ & V-VI & I & I & II & II & II & II & II & III \\
\hline \multicolumn{2}{|c|}{$\begin{array}{l}\text { 太湖新银鱼春群 }{ }^{*} \\
\text { Neosalanx taihuensis ( spring) }\end{array}$} & III & III & III -IV & IV $-\mathrm{V}$ & $\mathrm{V}$ & V-VI & I & I & I & II & II & II \\
\hline \multicolumn{2}{|c|}{$\begin{array}{l}\text { 太湖新银鱼秋群 * } \\
N . \text { taihuensis ( autumn) }\end{array}$} & I & I & I & I & I & I & II & II & III & IV $-\mathrm{V}$ & $\mathrm{V}$ & $\mathrm{V}-\mathrm{VI}$ \\
\hline \multicolumn{2}{|c|}{$\begin{array}{l}\text { 近太湖新银鱼 } \\
N . \text { pseudotaihuensis }\end{array}$} & III & III & III -IV & IV $-\mathrm{V}$ & V-VI & V-VI & I & I & II & II & II & II \\
\hline \multicolumn{2}{|c|}{ 有明银鱼 Salanx ariakensis } & I & I & I & I & I & I & II & II & II - III & IV $-\mathrm{V}$ & $\mathrm{V}$ & V-VI \\
\hline \multicolumn{14}{|c|}{$\begin{array}{l}\text { 表中 I-VI 表示卵巢发育时期, 其中 V 期为产卵期; ; 因太湖新银鱼在许多湖泊中具有春群和秋群分化，二者性腺发育周期不同，所以将其分 } \\
\text { The Roman letter I-VI denote the ovary development phases, and V is spawning phase. Due to the different paces between the spring-group and the a } \\
\text { tumn-group of the N.taihuensis, we present them both in the same table. Data from Xu (1965)，Zhang (1981)，Sun (1985) amd Wang (2000) } \\
\text { 表 } 4 \text { 6 种银鱼的生殖力统计表 } \\
\text { Table } 4 \text { The fecundity of the six icefish species }\end{array}$} \\
\hline \multirow[b]{2}{*}{$\begin{array}{c}\text { 类别 } \\
\text { Fecundity }\end{array}$} & \multicolumn{13}{|c|}{ 种类 Species } \\
\hline & \multicolumn{2}{|c|}{$\begin{array}{c}\text { 大银鱼 } \\
\text { Protosalanx } \\
\text { hyalocranius }\end{array}$} & \multicolumn{2}{|c|}{$\begin{array}{c}\text { 太湖新银鱼 } \\
\text { Neosalanx } \\
\text { taihuensis }\end{array}$} & \multicolumn{2}{|c|}{$\begin{array}{c}\text { 近太湖新银鱼 } \\
N . \text { pseudotaihuensis }\end{array}$} & \multicolumn{2}{|c|}{$\begin{array}{l}\text { 寡齿新银鱼 }^{*} \\
N . \text { oligodonties }\end{array}$} & \multicolumn{3}{|c|}{$\begin{array}{c}\text { 短吻间银鱼 } \\
\text { Hemisalanx } \\
\text { brachyrostralis }\end{array}$} & \multicolumn{2}{|c|}{$\begin{array}{c}\text { 有明银鱼 } \\
\text { Salanx ariakensis }\end{array}$} \\
\hline $\begin{array}{c}\text { 绝对怀卵量 } \\
\quad\left(\times 10^{3}\right) \\
\text { Absolute value }\end{array}$ & \multicolumn{2}{|c|}{$13.57 \sim 26.24$} & \multicolumn{2}{|c|}{$1.56 \sim 2.35$} & \multicolumn{2}{|c|}{$1.58 \sim 1.89$} & \multicolumn{2}{|r|}{-} & \multicolumn{3}{|c|}{-} & \multicolumn{2}{|c|}{10.61} \\
\hline $\begin{array}{c}\text { 相对怀卵量 } \\
\qquad\left(10^{3} / \mathrm{g}\right) \\
\text { Relative value }\end{array}$ & \multicolumn{2}{|c|}{$1.24 \sim 1.46$} & \multicolumn{2}{|c|}{$1.02 \sim 2.10$} & \multicolumn{2}{|c|}{$1.80 \sim 2.62$} & \multicolumn{2}{|c|}{$1.36 \sim 2.21$} & \multicolumn{3}{|c|}{$1.11 \sim 2.19$} & \multicolumn{2}{|c|}{1.47} \\
\hline
\end{tabular}

注: $*$ 为鄱阳湖银鱼数据, $* *$ 为鸭绿江的数据, 其他为太湖数据

* Data from Poyang Lake, ** Date from the Yalujiang River, and others from the Taihu Lake

以利于胚胎发育 (张玉玲, 1990)。不同银鱼物种在 繁殖生物学方面同样表现出丰富的多样性特征。

1) 种间繁殖时间分化明显: 同域分布的银鱼种 间产卵时间很少重叠, 产卵高峰彼此分离( 见表 3 ), 甚至于种内亦存在不同的繁殖群体, 如太湖新银鱼 就存在着春群和秋群甚至冬群 (滇池) 的分化 (陈宁 生, 1956 ; 朱成德, 1985; 高礼存,1989)。这一方面反 映了银鱼种间繁殖时间生态位的差异, 另一方面也 反映了银鱼对温度适应性的多样性特征。

2) 生殖力: 银鱼的相对怀卵量的平均值在 1400
～ 2000 粒/克体重之间（表 4 ），显著高于其他小型 鱼类 219 590 粒/克体重的相对生殖力 (高礼存, 1990 )。银鱼相对生殖力属内种间差异不显著（孙 帼英,1990; 唐作鹏，2000;Wang,2000），但属间差异 较为明显: 凶猛性银鱼 (如大银鱼、有明银鱼) 的生 殖力较低 (<1500 粒/克体重), 而植食性银鱼的生 殖力较高 (达到 2000 粒/克体重以上) (张开翔, 1981,1982 ;陈国华，1990）。这既反应了银鱼进化过 程中经受的选择压力的差异, 同时也反映了银鱼适 应环境的潜在能力的差异。 


\section{4 银鱼的生境异质性}

大的空间尺度上, 银鱼的产卵场、索饵场理化条 件差异明显，生境异质性很高: 从水体盐度特征看， 有适应于咸水环境的咸水生银鱼 (如有明银鱼, 居 氏银鱼等)，适应于淡水环境的淡水生银鱼 (如太湖 新银鱼, 寡齿新银鱼和短吻间银鱼等) 和在咸淡水 环境中产卵饵生活于咸水环境的洄游性银鱼 (如前 领间银鱼) 等。而从所生活水体的温度条件看, 银 鱼分布的 30 个纬度带包含了热带、亚热带、寒温带 的不同温度带，相应地也就具有南方种、北方种和广 温种的分化 (张玉玲,1993) ,或温水性和暖水性物 种之分 (解玉浩,1997)。这种大的空间范围的生境 差异和生态位分离不仅表现在种间,也表现在单个 物种内，如大银鱼就具有适应于不同盐度的生态类 型 (赫广春,2000)。对于同域分布的银鱼, 其适宜 生境的差异并不大, 种内和种间空间生态位分离也 不明显。种间的竞争共存主要是通过进化过程中形 成的时间和食性生态位的分离而实现的。

生境异质性的增加和保持是银鱼物种多样性形 成和得以保持的重要条件。因此银鱼生境异质性的 高低应该是银鱼保护生物学研究的一个重要组成部 分。

\section{5 中国银鱼资源现状及其衰退原因}

以上分析表明银鱼的适应性很强, 而我国银鱼 的生境异质性也很高，因此我国银鱼资源应该得到 很好的保护。然而事实并非如此，在过去的 50 年中 我国银鱼的天然资源遭到了巨大的破坏，资源现状 令人担忧。

\section{1 资源现状}

建国前，我国银鱼资源较为丰富，是我国北方沿 海及主要水系下游的主要渔获对象之一( 孙帼英, 1982 ;唐作鹏，1998），而现今我国天然银鱼资源衰退 十分严重。如鸭绿江河口及其沿海, 1952 年银鱼产 量达 $5.0 \times 10^{5} \mathrm{~kg}$ 现在只有零星的产量且年际波动 很大 (唐作鹏, 1998) ; 黄河流域的银鱼到 20 世纪 80 年代中期时已经难以采到了（Dou，1994) ;长江流 域的银鱼资源也同样: 1955 年长江口的前领间银鱼 年产量为 $2.44 \times 10^{5} \mathrm{~kg}, 1958$ 年为 $1.95 \times 10^{5} \mathrm{~kg}$ (陈 佩薰, 1963)。20 世纪 80 年代中期, 长江口的银鱼 年产量下降为数吨, 而到了 90 年代已经基本没有专
业银鱼生产。此外包括洞庭湖、鄱阳湖在内的长江 附属湖泊进入 90 年代以后, 大部分也停止了专业银 鱼生产，仅存的部分水域 (白沙长河、南渏湖等) 的 天然银鱼产量也降低到极小的规模。长江流域大银 鱼的空间分布范围已经缩小到下游的极少数水体， 长江特有种短吻间银鱼已属于易危 (另文发表)。

在天然银鱼资源严重衰退的同时,曾经作为我 国银鱼移植成功典范的滇池和岱海的银鱼也出现了 问题: 岱海的大银鱼在连续移植 9 年后获得了成功， 但第 10 年突然绝灭 (沈其璋,1997) ; 而滇池的太湖 新银鱼在 1998 年之后,其种群波动幅度增大, 产量 逐年下滑 (胡传林, 2000)。这些现象表明移植银鱼 同样存在着种群退化的问题。

\section{2 资源衰退的原因}

1) 产卵场破坏: 产卵场遭到破坏是银鱼资源衰 退的最主要的原因。因为银鱼是 $r$-对策者, 生殖力 高是其重要的生存竞争对策，任何影响其生殖成功 率的因素都会对其子代种群大小产生深刻的影响。 而产卵场的破坏直接导致其产卵规模、受精卵卵孚化 率和仔鱼成活率等的减小，从而极大地影响了其繁 殖成功率。围湖造田（陈国华，1986）和生境沼泽化 是导致银鱼产卵场缩减和质量下降的最直接的因 素。

2) 过度捕捞: 银鱼的经济价值高（鲜品价格在 $30 \sim 50$ 元 $/ \mathrm{kg}$ ), 银鱼生产是湖区渔民的重要经济来 源。传统的生产作业方式是利用渔汛 (产卵洄游或 产卵集群) 短期内高强度捕捞 ( 储益新, 1998; 唐作 鹏,1998)。对银鱼产卵亲体的过度捕捞造成有效 繁殖群体大小的锐减, 并引起种群的剧烈波动 (黄 真理 2001)。

3) 水体污染: 银鱼对环境变化敏感,污染水体 中银鱼种群数量锐减或消失。长江口前领间银鱼产 卵场的污染,造成了其产卵场的大幅度减少(张国 祥, 1992)，而工业污水的排放造成了鸭绿江口和辽 河河口的水体严重污染, 导致银鱼资源的急剧衰减 (唐作鹏,1998)。

4) 水位和水面面积下降：银鱼繁殖成功率与产 卵场水文条件显著相关(朱成德, 1982; 沈其璋, 1997 )。银鱼多为冷水性物种, 其产卵期多在枯水 季节( 隆冬或早春) ,水位降低、水面面积下降导致 银鱼的产卵场缩减，受精卵孵化率及幼鱼成活率降 低( 朱成德,1982)。 
5 ) 江湖阻隔和栖息地破碎化: 银鱼为大水面鱼 类, 难以在小水面内形成有效种群 (朱成德,1985)。 而小型湖泊间的个体交流对银鱼集合种群 ( metapopulation) 的建立和维持至关重要。在围湖造田 和湖泊自然演替导致湖泊水面缩小的情况下, 保持 江一湖、湖一湖沟通意义更为重大。但防洪大堤和 调蓄大闸等人工建筑阻隔了银鱼小群体间的交流, 使得生活于破碎化景观中的银鱼小群体的局部绝灭 (local extinction) 几率增加，对物种续存构成了直接 的威胁。

6 ) 现代渔业养殖经营模式 20 世纪 70 年代后， 我国四大家鱼的人工繁殖成功降低了鱼苗的价格， 从而极大地促进了鲢鳙的人工养殖力度。鲢鳙主食 浮游生物, 是银鱼的主要食物竞争者。所以鲢鳙的 高密度放养增加了银鱼的竞争压力, 影响了银鱼的 资源供给和银鱼的环境承载量。

总之银鱼资源的退化已成为普遍的现象, 但目 前对其退化原因和机制的研究还不透彻, 为了寻求 有效的保护措施，必须对天然银鱼资源进行深入的 调查，以了解银鱼资源的真实现状并分析致危因素， 有针对性地保护银鱼的生物多样性资源。

\section{6 中国银鱼生物多样性研究现状及其存在 的问题}

\section{1 研究现状}

1990 年以后, 我国银鱼研究工作呈现出两个重 要的趋向:一方面强调移植生产, 另一方面开始了分 子生物学方法应用于银鱼遗传多样性的研究。

银鱼移植增殖和开发研究开始于 1979 年, 至今 已有 20 多年的历史 (高礼存, 1989 ;蓝学恒,1998)， 其间大银鱼和太湖新银鱼已经被移植到全国 20 多 个省市的水库或湖泊等大型水域 (胡传林,2000)。 伴随着银鱼移植增殖工作的广泛深入的开展, 关于 银鱼移植的研究报道逐年增多，据不完全统计，我国 自 1994 2001 年所发表的有关银鱼的研究论文中 关于银鱼的移植和开发的报道就占 $45.3 \%$ 。

分子生物学方法开始应用于银鱼研究, 目前所 见报道有寡齿新银鱼的同工酶与幼态持续的关系的 研究 (林信伟,1991)、银鱼的遗传多样性特征的 RAPD 标记分析 (夏德全,1999 2000) 等。这些工作 虽然只是起步阶段的探索, 但已经显示出在银鱼的 系统学和进化生物学研究中的巨大潜力。相信银鱼
遗传物质的分子生物学研究必将在银鱼的分类和系 统学研究以及银鱼进化分化研究等领域发挥重要作 用。

\section{2 中国银鱼研究工作中存在的不足}

总的看来, 我国银鱼研究缺乏远见和系统性, 仅 限于为眼前的经济利益所驱使而开展的与生产和开 发密切相关的理论和技术研究, 这对于银鱼多样性 的保护和资源的长期可持续利用是极为不利的。

1 ) 基础研究较为薄弱。这主要表现在:(1) 研 究对象不够全面:已有的研究工作局限于与生产开 发关系密切的大银鱼、太湖新银鱼、寊齿新银鱼和前 领间银鱼等少数几种经济价值较大的银鱼品种, 远 未覆盖整个银鱼区系; (2) 研究区域过于集中 :对银 鱼基本生物学的研究区域主要集中在长江中下游一 带，而有关其他流域水体的研究报道极少，因而限制 了对银鱼的空间分布格局以及大的时间尺度上的银 鱼种群或群落的动态的认识和把握; 3 研究层次不 够深入 绝大部分工作都是关于种群生物学或种群 生态学的研究, 未能扩展到群落或生态系统的高度。 这也是银鱼移植成功率低的症结所在。

2 ) 对资源现状的了解不够。有限的资源调查 主要在长江流域开展（陈国华，1985;王国平，1995； 储益新,1998) , 而缺乏全国范围的大范围的专项调 查研究, 因此远未能从总体上反映全国天然银鱼资 源的状况。因此有必要开展全国范围的天然银鱼资 源调查, 为银鱼多样性保护提供本底资料。

3 ) 保护生物学研究亟待加强。几乎没有开展 针对大的空间范围内的银鱼种群动态等生态学过程 的研究, 对银鱼资源变动的机制缺乏应有的了解，从 而限制了保护工作的开展。

4 ) 对银鱼移植的生态风险重视不够。有研究 表明，银鱼引进或入侵对云南滇池、抚仙湖等水体的 土著鱼类和水体生态系统已经造成了巨大的影响 (Xie ,1999)。但这类现象没有受到应有的重视, 也 没有开展相应的生态监测研究。所以我国银鱼移植 工作带有极大的生态风险，对此应当引起足够的重 视，积极开展银鱼移植工作的生态风险评估，以防止 造成不必要的损失。

\section{7 结语和建议}

银鱼对环境变化非常敏感，因此不失为研究生 物与环境间生态关系的良好指示物种。加强对其基 
本生物学、生态学和保护生物学研究, 用以保护天然 银鱼的种质资源，必将带来巨大的经济效益和生态 效益。中国是世界上银鱼最主要的分布区，拥有绝 大多数的银鱼种类，物种多样性和生境异质性高，这 决定了中国银鱼保护工作在世界银鱼资源保护和恢 复中的举足轻重的作用。

长江流域是银鱼最集中的分布区 (共分布有 2 亚科 4 属 10 种），也是我国乃至世界天然银鱼的主 要产区和我国银鱼移植工作的主要种质资源供应 地。同时长江流域具有许多得天独厚的优越地理条 件: 水量充沛、水资源丰富、生境稳定，湖泊众多且生 境复杂多样, 异质性高。因此, 从客观上说长江中下 游是银鱼多样性研究和保护的关键地区，在银鱼生 物多样性保护中具有不可替代的作用和地位。加强 长江流域银鱼的保护生物学研究具有巨大的理论和 现实意义。因此可以长江中下游为中心开展银鱼的 生境治理和生物多样性保护试点研究工作。

我们建议从以下 5 个方面着手开展天然银鱼的 生物多样性保护工作 :

1 ) 加强现有天然银鱼生产的管理, 合理规划捕 捞时间，以提高产品规格和经济效益。同时采取紧 急措施开展对银鱼产卵期和幼鱼期的禁捕, 以减缓 天然银鱼资源衰退的势头。

2) 开展银鱼资源调查工作, 目的是了解我国银 鱼资源的真实现状，从而为制定银鱼资源保护和开 发的战略方针提供本底资料。

3) 开展对银鱼移植增殖工作的评估, 目的是明 确银鱼移植工作的总体短期经济效益、长期经济效 益和其生态入侵所具有的潜在的生态代价。加强对 银鱼移植水体的生态监测, 掌握移植水体的生态学 动态变化, 以防止银鱼移植对环境的负面影响的扩 大。

$4)$ 加强银鱼的生物学和生态学研究, 我国银鱼 移植开发工作是基于 20 世纪 80 年代的基础研究 的。但如前所述我国银鱼的基本生物学研究还存在 着许多不足, 这既影响了银鱼移植工作中成功率和 可预测性，同时也限制了合理的保护措施的制定和 实施。

5 ) 开展保护生物学和恢复生态学研究, 以长江 流域为依托, 研究银鱼的种群动态及其与环境变化 间的互动关系，以了解银鱼资源变化的关键因子并 开展相关的恢复生态学研究。通过加强管理工作力
度，保护银鱼的自然增殖; 同时积极配合退田还湖的 政策，恢复江湖沟通关系，逆转生境破碎化的局面， 为银鱼多样性的保护和持续利用奠定基础。

致谢:承蒙张开翔、朱成德、孙帼英老师无私提供资 料或经验指导，解玉浩、刘玉明老师 E-mail 回答作 者关于鱼类分类方面的问题，同时得到熊邦喜、窦鸿 身、张堂林、王卫民老师的热情帮助，在此一并表示 衷心的感谢。最后特别感谢两位匿名审稿老师的指 导和帮助。

\section{参考文献}

陈国华, 张本, 1990. 鄱阳湖产银鱼的繁殖生物学. 湖泊科 学, 2(1): $59 \sim 67$

陈国华, 张本, 1991. 鄱阳湖产银鱼生长的研究. 江西科学, 9 (4) : $225 \sim 232$

陈国华, 李伟明, 戴年华, 1986. 鄱阳湖银鱼的产卵场的调 查. 淡水渔业, (5): 13 16

陈宁生, 1956. 太湖所产银鱼的初步研究. 水生生物学集刊, (2) : $324 \sim 335$

陈佩薰, 黄鹤年, 1963. 长江三角洲面鱼的形态生态资料. 水 生生物学集刊, (3) : 93 98

成庆泰, 郑葆珊, 1987. 中国鱼类系统检索. 北京: 科学出版 社, $1 \sim 643$

储益新, 1998. 南㫊湖银鱼资源衰退及对策. 安徽农业科学, 26(1) : $84 \sim 86$

高礼存, 庄大栋, 迟金钊, 1989. 太湖短吻银鱼移植滇池实验 研究. 湖泊科学, 1(1): 79 88

高礼存, 庄大栋, 郭起治, 王幼槐, 1990. 云南湖泊鱼类资源. 南京: 江苏科学技术出版社, $39 \sim 42$

龚世园, 张训蒲, 李跃云, 张建伟, 1995. 淤泥湖近太湖新银 鱼的生长研究. 水利渔业, (5): 1 11

龚世园, 龚世园, 罗作兵, 刘军, 何绪刚, 张训蒲, 吴敏生, 金顶 玄, 汪庆佩, 谭献礼, 1999. 富水水库太湖新银鱼食性的 初步研究. 水利渔业, 19(3): 7 9

何文辉, 赫广春, 尤洋, 胡庚东, 王博, 2001。大银鱼和太湖新 银鱼摄食器官和食性研究. 青海畜牧兽医杂志, 31(1): $12 \sim 13$

何文辉, 赫广春, 尤洋, 郭祖峰, 张晓, 2000. 不同纬度太湖新 银鱼的食性比较及其饵料生物学容量评价. 青海畜牧 兽医杂志, 30(5) : $11 \sim 12$

赫广春, 何文辉, 董秀清, 尤洋, 胡庚东, 2000. 不同生态种群 大银鱼生物学特性的比较. 青海畜牧兽医杂志, $30(2)$ : $20 \sim 23$

胡传林, 白宏, 陈文祥, 刘家寿, 2000. 银鱼产业化经营的途 径探讨. 水利渔业, 20(4): 1 2

黄真理, 常剑波, 2001. 银鱼的产量能预报吗? 生态学报, 21 (1) : $86 \sim 93$

蓝学恒, 张德斌, 冀喜平, 蓝巨宁, 任彩景, 1998. 岱海移殖大 银鱼十年总结一一第 9 年才成功第 10 年突然绝迹原因 分析. 大连水产学院学报, 13(1): 41 46

李明德, 1998. 鱼类分类学. 北京: 海洋出版社, $116 \sim 120$

林信伟, 熊全沫, 1991. 寊齿新银鱼同工酶及其与幼态持续 的关系. 遗传学报, 18(3): 214 218

刘明玉, 解玉浩, 季达明, 2000. 中国脊椎动物大全. 沈阳: 辽宁大学出版社, $168 \sim 172$ 
刘正文, 朱松泉, 1994. 滇池产太湖新银鱼食性与摄食行为 的初步研究. 动物学报, 40(3): 253 261

荣长宽, 岳炳宜, 1998. 天津大银鱼仔、幼鱼的食性. 水产科 技情报, 25(5): 24 26

沈其璋, 喻叔英, 1997. 岱海大银鱼消失原因分析. 内蒙古农 业科技, (1):9 11

施炜纲, 周昕, 陈家涤, 钱继仁, 杜晓燕, 1998. 生态因子对大 银鱼受精卵孵化和仔鱼存活率的影响. 水产学报, 22 (4) : $375 \sim 377$

孙帼英, 1990. 长江口及其邻近海域有明银鱼的生物学. 海 洋湖沼通报, (1): $41 \sim 46$

孙帼英, 1985. 大银鱼卵巢的成熟期和产卵类型. 水产学报, 9(4) : $363 \sim 368$

孙帼英, 1982. 长江口及其邻近海域的银鱼. 华东师范大学 学报(自然科学版), (1): 111 119

孙帼英, 周忠良, 1989. 长江口及其临近海域大银鱼生态的 初步研究. 海洋湖沼通报, (4) : 76 79

唐作鹏, 解玉浩, 富丽静, 张世东, 1998. 辽宁沿海银鱼资源 调查和主要银鱼群体结构的研究. 海洋湖沼通报, (1): $44 \sim 50$

唐作鹏, 解涵, 李勃, 解玉浩, 张世东, 于福, 2000. 鸭绿江有 明银鱼的生物学研究. 大连水产学院学报, 15(2): 113 $\sim 118$

王国平, 1995. 洞庭湖太湖短吻银鱼环境资源现状的调查. 内陆水产, (3): 11

王卫民, 杨干荣, 张家波, 樊启学, 刘兴国, 陈希亮, 程志学, 尚 士正, 熊庆员, 1996. 徐家河水库陆封近太湖新银鱼生 长特性及其渔业利用. 水产学报, 20(1): 18 24

王文滨, 朱成德, 锤瑄世, 陈素芝, 张玉玲, 1982. 太湖短吻银 鱼春季早期胚胎发育及温度与其孵化关系的研究. 生 态学报, 2 (1)：67 76

王文滨, 张世界羲, 锤瑄世, 顾良伟, 朱成德, 李高铭, 杨悦, 1990. 太湖新银鱼周年生长计算的初步分析. 水产学 报, 14(2): 137 143

王文滨, 朱成德, 锤瑄世, 张玉玲, 陈素芝, 1980。太湖短吻银 鱼秋季人工授精、孵化和早期胚胎发育的研究. 水产学 报, 4 (3): $303 \sim 307$

王玉芬, 蒋全文, 1992. 太湖大银鱼生长特性的研究. 湖泊科 学, 4(1): $56 \sim 62$

伍献文, 林人端, 1965. 银鱼的幼态持续及其在天演上的意 义. 水生生物学集刊, 5(2):239 248

夏德全, 曹萤, 吴婷婷, 杨弘, 1999. 太湖中大银鱼、太湖新银 鱼和寡齿新银鱼群体的遗传结构. 水产学报, 23 (3): $254 \sim 260$

夏德全, 曹萤, 吴婷婷, 杨弘, 2000. 用 PAPD 方法分析太湖大 银鱼、太湖新银鱼和寡齿新银鱼的亲缘关系. 中国水产 科学, 7(1): 12 15

解玉浩, 解涵, 1997. 银鱼科鱼类的分类分布和种群生态. 水 产学杂志, 10(2): 11 19

熊传喜, 杨干荣, 王宝林, 1994. 太湖新银鱼和葟齿新银鱼的 营养成分分析. 淡水渔业, 24(6):7 9

徐信, 陆厚基, 1965. 太湖短吻银鱼 (Neosalanx tangkahkeii var. taihuensis) 性腺发育阶段分期及产卵期的探讨. 华 东师范大学学报 (自然科学版), (2): 67 73

殷国俊, 曹克驹, 余志堂, 龚世园, 1997. 网湖银鱼的繁殖、食 性与生长. 湖泊科学, 9(1):63 70

张开翔, 1984. 太湖产乔氏短吻银鱼的胚胎发育. 水产学报, $\mathbf{8}(2): 161 \sim 170$

张开翔, 高礼存, 张立, 1982. 洪泽湖所产太湖短吻银鱼的初 步研究. 水产学报, 6(1):9 16

张开翔, 庄大栋, 张立, 1981. 洪泽湖所产大银鱼生物学及其
增殖的研究. 水产学报, 5(1):29 41

张开翔, 1992. 大银鱼胚胎发育的观察. 湖泊科学, 4(2): 25 $\sim 37$

张国翔, 1992. 前领间银鱼资源变动原因的初步研究. 海洋 与湖沼, 23(5): 517 526

张世东, 1999. 鸭绿江银鱼资源回升的相关因素分析. 中国 渔业经济研究, (3):32

张玉玲, 1987. 中国新银鱼属 Neosalanx 的初步整理及其一 新种. 动物学研究, 8(3):277 286

张玉玲, 1990. 十三种银鱼卵膜丝形态的初步观察. 水产学 报, 14(1): $44 \sim 49$

张玉玲. 1991. 新银鱼属系统发育的初步研究. 见: 张广学 (主编), 系统进化动物学论文集(第一集). 北京: 中国 科学技术出版社, $75 \sim 82$

张玉玲, 1985. 银鱼属 SALANX 模式种的同名, 异名和分布. 动物分类学报, 10(1): 111 112

张玉玲, 1993. 银鱼科鱼类系统生物地理学初步研究. 见: 张 广学(主编), 系统进化动物学论文集(第二集). 北京: 中国科学技术出版社, $65 \sim 77$

朱成德, 1982. 太湖银鱼产量与水位关系的数理统计分析. 淡水渔业, (4) : 40 42

朱成德, 1985 . 不同温度对太湖短吻银鱼秋季孵化的试验研 究. 生态学报, 4(1): 65 72

Dou S Z and D G Chen, 1994. Taxonomy, biology and abundance of icefishes, or noodoefishes (Salangidae), in the Yellow River estuary of the Bohai Sea, China. Journal of Fish Biology, 45: $737 \sim 748$

Fang P W, 1934a. Study on the fishes referring to Salangidae of China. Sinensia, 4(9): $231 \sim 268$

Fang P W, 1934b. Supplementary notes on the fishes referring to Salangidae of China. Sinensia, 5(5\& 6) : $505 \sim 511$

Gumaa S A, 1978. The food and feeding habits of young perch, Perca fluiatilis, in wendernere. Freshwater Biology, 8:177 $\sim 187$

Liu Z W, A Herzig and R schiemer, 2000. Growth of the icefish Neosalanx Pseudotaihuensis (Salangidae) in Xujiahe Reservoir, central China. Environmental Biology of Fishes, (59) : $219 \sim 227$

Nelson J S, 1994. Fishes of the World (3rd edition). John Wiley \& Sons Inc., New York, $1 \sim 600$

Osbeck P, 1757. Dagbok äfver en ostindesk Resa ären 175052, med anmärkningar uti Naturkunnighiten, främmende spräk, etc. Stockholm, 6: $1 \sim 376$

Pyke G H, 1984. Optimal foraging theory: a critical review. Annual Research of Ecological Systematics, 15: $523 \sim 575$

Regan C T, 1908. A synopsis of fishes of the subfamily Salangidae. Annual Magzine of Natural History, 8(2): $444 \sim 446$

Rendahl H, 1932. Eine neue art famalie Salangidae aus China. Zoologischer Anzeiger, 56(3 4): 92

Wang W M and A Yakupitiyage, 2000. Reproductive biology of icefish (Neosalanx pseudotaihuensis zhang) in Xujiahe Reservoir. Journal of huazhong Agricultural University, 2000, 19(3) : $261 \sim 267$

Wakiya Y and N Takahasi, 1937. Study on fishes of the family Salangidae. Journal of College of Agriculture, 14 (4) : 265 $\sim 303$

Xie P and Y Y Chen, 1999. Threats to biodiversity in Chinese inland waters. $A M B I O, 28(8): 54 \sim 61$

(责任审稿人 :胡传林; 责任编辑 : 问文杰, 孙大川) 